\section{Effect of Carbamide Peroxide Bleaching Gel on Composite Resin Flexural Strength and Microhardness}

Gabriel Rodrigues Hatanaka, Filipe de Oliveira Abi-Rached, Antonio Alves de Almeida-Júnior, Carlos Alberto dos Santos Cruz
Department of Dental Materials and Prosthodontics, Araraquara Dental School, UNESP - Univ Estadual Paulista, Araraquara, SP, Brazil

Correspondence: Prof. Dr. Carlos Alberto dos Santos Cruz, Rua Humaitá, 1680, 14801-903 Araraquara, SP, Brasil. Tel: +55-16-3301-6425. e-mail: cruz@foar.unesp.br

\begin{abstract}
This study investigated the effect of 16\% carbamide peroxide (Whiteness Perfect/FGM) on the Vickers microhardness and flexural strength of the restorative composites Filtek Z100 (hybrid), Filtek Z350 (nanofill), Brilliant (micro-hybrid) and Opallis (micro-hybrid). Discshaped $(4 \times 2 \mathrm{~mm} ; \mathrm{n}=5)$ and bar-shaped $(12 \times 2 \times 1 \mathrm{~mm} ; \mathrm{n}=10)$ specimens of each restorative material were randomly divided into 2 groups: $(\mathrm{G} 1) 16$ weeks stored in distilled water; (G2) 16 weeks stored in distilled water, with 16\% carbamide peroxide application during $6 \mathrm{~h}$ per day for the last 4 weeks. The mechanical properties were evaluated using a Vickers microhardness tester and a mechanical testing machine. Data were analyzed by twoway ANOVA and Tukey's (HSD) post-hoc test $(\alpha=0.05)$. Filtek Z100 presented the highest microhardness value, followed by Filtek Z350 and finally by Brilliant and Opallis $(p=0.00)$. Filtek Z100 and Brilliant exhibited the highest flexural strength value, followed by Filtek Z350 and Opallis $(p=0.00)$. Bleaching treatment decreased significantly microhardness of Brilliant and Opallis $(p=0.00)$. The flexural strength of all studied materials was not affected by the home bleaching $(p=0.28)$.
\end{abstract}

Key Words: bleaching agents, hardness, strength, composite resins.

\section{Introduction}

Dental bleaching has been widely used in dentistry as an effective and non-invasive aesthetic dental treatment (1). Different techniques may be employed for brightening discolored teeth, such as: home bleaching, in-office bleaching or a combination of both (2). Since its introduction by Haywood and Heymann (3), home bleaching has become an attractive treatment modality for patients and dentists due to its excellent clinical effectiveness, easy application, lower cost and safety of the used materials $(1,4)$. In general, as cited by Attin et al. (5), this technique uses low-concentration peroxide-containing agents generally with a low cost individual tray for 2-4 weeks and application intervals of 4-8 $\mathrm{h}$ per day. A 10-17 years follow-up study (4) showed that home bleaching provided patient satisfaction with minimal side effects.

One of the products used for this procedure is the carbamide peroxide at 10-16\% concentrations, which degrades into free radicals $\left(\mathrm{OH}^{-}\right)$when in contact with saliva. The breakdown of large pigmented molecules into smaller ones by these free radicals modifies the reflected wavelength of light and consequently changes the teeth color and translucency (6). As the bleaching agents are not able of influencing the optical properties of restorative materials, they must be replaced on the anterior teeth if aesthetically unsatisfactory (5). However, after dental bleaching, it is not necessary to replace functionally acceptable posterior restorations. Thus, studies have investigated the effects of bleaching agents on several restorative materials used in the posterior region of oral cavity, such as amalgam (7), composite resins (8-13), glass ionomer cement $(11,13,14)$ and feldspathic porcelain $(11,14)$. According to these studies, bleaching agents are able to modify the porosity (14), hardness (15), flexural strength (13) and color stability (16) of restorative composites.

Considering the increasing use of aesthetic restorative materials on posterior teeth, as well as the dental bleaching procedures, it is important to evaluate the effect of bleaching agents on the mechanical properties of composite resin restorations. Thus, the aim of this study was to investigate the effect of $16 \%$ carbamide peroxide for 4 weeks by $6 \mathrm{~h}$ per day on the Vickers microhardness and flexural strength of 4 restorative composites.

\section{Material and Methods}

The restorative materials evaluated in this study are summarized in Table 1. Photoactivation was performed with a visible light-curing unit (Optilight Plus; Gnatus Equipamentos Médico-Odontológicos Ltda, Ribeirão Preto, $\mathrm{SP}$, Brazil) at an irradiance of $500 \mathrm{~mW} / \mathrm{cm}^{2}$, which was assessed with a radiometer (DMC Equipamentos Ltda, São Carlos, SP, Brazil) prior to each use.

To prepare specimens for the microhardness test $(n=5)$, composite resins were inserted in a single increment into circular autopolymerizing acrylic resin matrices $(4.0 \mathrm{~mm}$ diameter and $2.0 \mathrm{~mm}$ deep). A glass slab and a metal disc 
of $1.0 \mathrm{~kg}$ were placed on top of the materials during their photoactivation. The composite resins were polymerized for $40 \mathrm{~s}$ by the metal disc opening/aperture. During this procedure, the tip of the light-curing unit was in contact with the glass slab surface. After that, all specimens were smoothed with 600- and 1200-grit silicon carbide sandpapers in a polishing unit (Metaserv 2000; Buehler UK Ltd, Coventry, UK).

For the flexural strength test $(n=10)$, bar-shaped specimens (12 mm long $\times 2 \mathrm{~mm}$ wide $\times 1 \mathrm{~mm}$ high) were produced by a custom-made metal split matrix. The restorative composites were inserted as previously mentioned and light-cured for $120 \mathrm{~s}$ (40 s in each length of approximately $4 \mathrm{~mm}$ ).

The specimens of each restorative material were randomly divided into 2 groups: (G1) 16 weeks stored in distilled water, without bleaching agent application; (G2) 16 weeks stored in distilled water, with 16\% carbamide peroxide (Whiteness Perfect; FGM Produtos Odontológicos, Joinville, SC, Brazil) application during $6 \mathrm{~h}$ per day for the last 4 weeks. The bleaching gel was applied directly on the top of the bleaching surfaces with a $0.5 \mathrm{~mm}$ thickness. Throughout the experiment, all specimens were kept inside a lightproof recipient at $37 \pm 1{ }^{\circ} \mathrm{C}$.

For the surface microhardness measurements, a Vickers microhardness tester (model 1600-6300; Buehler, Lake Bluff, IL, USA) was used with a $0.98 \mathrm{~N}$ load and $30 \mathrm{~s}$ dwell time. Eight microhardness measurements were obtained on the top surface of each specimen. Three-point flexural strength test was performed with a mechanical testing machine (EMIC DL2000; EMIC Equipamentos e Sistemas de
Ensaio Ltda, São José dos Pinhais, PR, Brazil) at a crosshead speed of $0.5 \mathrm{~mm} / \mathrm{min}$.

Data were analyzed statistically by two-way ANOVA and Tukey's (HSD) post-hoc test at a significance level of $5 \%$.

\section{Results}

The microhardness and flexural strength data are presented in Tables 2 and 3, respectively.

Filtek Z100 presented the highest hardness value, followed by Filtek Z350 and finally by Brilliant and Opallis, which showed statistically similar hardness values $(p=0.00)$. Bleaching treatment adversely affected only Brilliant and Opallis $(\mathrm{p}=0.00)$.

Filtek Z100 and Brilliant exhibited the highest mean flexural strength value, followed by Filtek Z350 and Opallis $(p=0.00)$. The bleaching agent did not produce any statistically significant influence on the flexural properties of the tested restorative materials $(p=0.28)$.

\section{Discussion}

The results of the present study showed statistical differences among the restorative materials. The mechanical properties of composite resins are determined by the interaction of several factors, such as composition, degree of conversion of polymer chains, filler volume-fraction, filler particle size and distribution, and the interfacial properties between the filler and resin matrix $(17,18)$. Thus, the higher filler content (71\%) of Filtek Z100 hybrid composite may have contributed to the higher hardness performance (81.7 $\mathrm{VHN} / 81.5 \mathrm{VHN}$ ) of this composite in relation to the other

Table 1. Materials evaluated

\begin{tabular}{|c|c|c|c|c|c|}
\hline Material & Type & Matrix & Filler & Shade & Batch\# \\
\hline $\begin{array}{c}\text { Filtek Z100 } \\
\text { 3M/ESPE, St. } \\
\text { Paul, MN, USA }\end{array}$ & Hybrid & Bis-GMA/TEGDMA & $\begin{array}{c}\text { Zirconia/silica } \\
4.5 \mu \mathrm{m} \text { (maximum size) } \\
71 \text { vol\% }\end{array}$ & A 3.5 & 7EP \\
\hline $\begin{array}{c}\text { Filtek Z350 } \\
\text { 3M/ESPE, St. } \\
\text { Paul, MN, USA }\end{array}$ & Nanofill & $\begin{array}{c}\text { Bis-GMA/UDMA } \\
\text { Bis-EMA/TEGDMA }\end{array}$ & $\begin{array}{c}\text { Zirconia/silica } \\
0.005-0.02 \mu \mathrm{m} \\
\text { (cluster size } 0.6-1.4 \mu \mathrm{m} \text { ) } \\
59.5 \text { vol\% }\end{array}$ & A 3.5 & 9AK \\
\hline $\begin{array}{l}\text { Brilliant } \\
\text { Coltène Whaledent AG } \\
\text { Altstätten, Switzerland }\end{array}$ & Micro-hybrid & Methacrylates & $\begin{array}{c}\text { Silica } \\
0.5 \mu \mathrm{m} \text { (mean size) } \\
58.5-59 \text { vol\% }\end{array}$ & A 3.5 & 0126172 \\
\hline $\begin{array}{c}\text { Opallis } \\
\text { FGM Odontological } \\
\text { Products, Joinville, } \\
\text { SC, Brazil }\end{array}$ & Micro-hybrid & $\begin{array}{c}\text { Bis-GMA/UDMA } \\
\text { Bis-EMA/TEGDMA }\end{array}$ & $\begin{array}{c}\text { Silica } \\
0.5 \mu \mathrm{m} \text { (mean size) } \\
57-58 \text { vol } \%\end{array}$ & A 3.5 & 211107 \\
\hline
\end{tabular}

Bis-GMA: bisphenol-A diglycidylether dimethacrylate. Bis-EMA: bisphenol-A ethoxylated dimethacrylate. TEGDMA: triethylene glycol dimethacrylate. UDMA: uretane dimethacrylate. 
tested restorative materials. However, among the other composites, which present filler volume-fraction around $60 \%$, was observed a higher hardness value of Filtek Z350 nanofilled composite (55.5 VHN/52.9 VHN) when compared to Brilliant (47.9 VHN/43.5 VHN) and Opallis (45.3 VHN/40.7 VHN) micro-hybrid composites. This better behavior of Filtek Z350 is possibly related to the effect of composition and degree of conversion of the polymer matrix on hardness, as well as the resin matrix greater mechanical strength, as reported by Ferracane et al. (18). Another important factor that might have contributed to the higher hardness value of Filtek Z350 nanofilled composite was the higher resistance of the aggregated zirconia/silica cluster filler to the Vickers indenter.

For the flexural strength of the evaluated materials, the filler volume-fraction does not seem to be a decisive factor, as Filtek Z100 hybrid composite (71\%) and Brilliant microhybrid composite (around 60\%) exhibited statistically similar mean flexural strength values (141.7 MPa/127.7 $\mathrm{MPa}$ and $145.7 \mathrm{MPa} / 119.2 \mathrm{MPa}$, respectively). Assuming that during the flexural strength tests, the crack propagation in the specimen is intergranular (11), probably the chemical bonds promoted by silane coupling agent at resin-filler interface may also have influenced this mechanical property (19), promoting a balance between the composite resins, despite their different volume of filler particles. Filtek Z350 nanofilled and Opallis microhybrid composites showed significantly different flexural strength values between them (84.1 MPa/106.2 $\mathrm{MPa}$ and 85.2 MPa/83.7 MPa, respectively) and lower than Brilliant (145.7 MPa/119.2 $\mathrm{MPa})$, although these three composite resins contain similar filler volume fraction. This fact demonstrates that the composition and degree of conversion of the resin matrix, as well as the amount of filler particles are not the only factors affecting the mechanical strength of restorative composites. The lower flexural strength value of Filtek $Z 350$ nanofilled composite when compared to Filtek Z100 hybrid and Brilliant microhybrid composites was the result of a

Table 2. Mean microhardness values (VHN), standard deviations $( \pm)$ and statistical results

\begin{tabular}{lcc}
\hline Composite resin & G1 & G2 \\
\hline Filtek Z100 & $81.7 \pm 1.9^{\text {Аa }}$ & $81.5 \pm 2.4^{\text {Аa }}$ \\
Filtek Z350 & $55.5 \pm 1.6^{\text {Ba }}$ & $52.9 \pm 1.9^{\text {Ba }}$ \\
Brilliant & $47.9 \pm 0.4^{\mathrm{Ca}}$ & $43.5 \pm 2.9^{\mathrm{Cb}}$ \\
Opallis & $45.3 \pm 1.5^{\mathrm{Ca}}$ & $40.7 \pm 3.1^{\mathrm{Cb}}$ \\
\hline
\end{tabular}

Standard error $=0.70$. Critical value $(5 \%)=3.15$. Different lowercase superscripted letters indicate statistically significant differences in rows $(p<0.05)$. Different uppercase superscripted letters indicate statistically significant differences in columns $(\mathrm{p}<0.05)$. possible negative effect of the aggregated zirconia/silica cluster filler, which favored the crack propagation (11).

The literature has shown contradictory results for the effect of bleaching agents on microhardness of composite resins (20). Some studies reported an increase $(9,21)$, others a decrease $(8,22,23)$ or no change $(10,24)$ in composite surface hardness after application of carbamide peroxide agents, reflecting, aside the composition of composite resins, the effect of specimen aging during the moment of bleaching procedure (18).

The softening effect of bleaching agent on Brilliant and Opallis microhardness may have occurred by the breakdown of carbamide peroxide into free radicals which may induce oxidative cleavage of polymer chains $(11,12)$. However, the same phenomenon was not observed for Filtek Z100 and Filtek Z350, possibly by their different composition of monomer resins, which are not susceptible to the previously mentioned oxidative reaction.

The adverse effects of bleaching procedure for the microhardness tests were not observed in flexural strength tests, perhaps because the resistance of the silane coupling agent to the oxidative cleavage or by the short period of exposure.

Finally, it should be taken into account the bleaching treatment protocol, as home bleaching uses lowconcentration peroxide-containing agents. Studies that evaluate more intensive protocols, such as the combination between home bleaching and in-office bleaching, as well as the association with light and heat, should be conducted, since these methods may enhance the adverse effects of the bleaching agents over the mechanical strength of composite resins.

Under the conditions of this study, the following conclusions can be drawn: 1 . Filtek Z100 presented the highest hardness value, followed by Filtek Z350 and finally by Brilliant and Opallis, which showed similar behavior; 2. Filtek Z100 and Brilliant exhibited the highest flexural strength value, followed by Filtek Z350 and Opallis; 3 . Home

Table 3. Mean flexural strength values (MPa), standard deviations $( \pm)$ and statistical results

\begin{tabular}{lcc}
\hline Composite resin & G1 & G2 \\
\hline Filtek Z100 & $141.7 \pm 19.8^{\text {Аа }}$ & $127.7 \pm 32.4^{\text {Аа }}$ \\
Filtek Z350 & $84.1 \pm 15.8^{\text {Ва }}$ & $106.2 \pm 21.5^{\text {АВа }}$ \\
Brilliant & $145.7 \pm 18.3^{\text {Аа }}$ & $119.2 \pm 21.5^{\text {Аа }}$ \\
Opallis & $85.2 \pm 14.9^{\text {Ва }}$ & $83.7 \pm 12.6^{\text {Ва }}$ \\
\hline
\end{tabular}

Standard error $=6.45$. Critical value $(5 \%)=28.13$. Different lowercase superscripted letters indicate statistically significant differences in rows $(p<0.05)$. Different uppercase superscripted letters indicate statistically significant differences in columns $(p<0.05)$. 
bleaching treatment showed negative effects on hardness of Brilliant and Opallis; 4 . The flexural strength of bleached materials remained unchanged.

\section{Resumo}

Este estudo investigou o efeito do peróxido de carbamida a 16\% (Whiteness Perfect/FGM) na dureza Vickers e resistência à flexão dos compósitos restauradores Filtek Z100 (hibrida), Filtek Z350 (nanoparticulada), Brilliant (micro-hibrida) e Opallis (micro-híbrida). Espécimes em forma de disco (4x2 $\mathrm{mm} ; \mathrm{n}=5)$ e de barra $(12 \times 2 \times 1 \mathrm{~mm} ; \mathrm{n}=10)$ de cada material restaurador foram distribuidos aleatoriamente em 2 grupos: (G1) 16 semanas em água destilada; (G2) armazenamento em água destilada durante 16 semanas, com aplicação do peróxido de carbamida a 16\% por $6 \mathrm{~h}$ diárias nas últimas 4 semanas. As propriedades mecânicas foram avaliadas em microdurômetro Vickers e máquina de ensaios mecânicos. Os dados foram analisados por ANOVA a 2 critérios e teste de Tukey $(\alpha=0,05)$. Filtek $Z 100$ apresentou o maior valor de dureza, seguido por Filtek Z350 e, finalmente, por Brilliant e Opallis $(p=0,00)$. Filtek Z100 e Brilliant mostraram o maior valor de resistência à flexão, seguido por Filtek Z350 e Opallis $(p=0,00)$. 0 clareamento diminuiu significantemente a dureza das resinas Brilliant e Opallis $(p=0,00)$. A resistência à flexão dos materiais estudados não foi afetada pelo clareamento caseiro $(p=0,28)$.

\section{References}

1. Haywood VB. History, safety, and effectiveness of current bleaching techniques and applications of the nightguard vital bleaching technique. Quintessence Int 1992;23:471-488.

2. Heymann HO. Tooth whitening: facts and fallacies. $\mathrm{Br}$ Dent J 2005;198:514.

3. Haywood VB, Heymann HO. Nightguard vital bleaching. Quintessence Int 1989;20:173-176.

4. Boushell LW, Ritter AV, Garland GE, Tiwana KK, Smith LR, Broome A, et al.. Nightguard vital bleaching: side effects and patient satisfaction 10 to 17 years post-treatment. J Esthet Restor Dent 2012;24:211-219.

5. Attin T, Hannig C, Wiegand A, Attin R. Effect of bleaching on restorative materials and restorations - a systematic review. Dent Mater 2004;20:852-861.

6. Polydorou 0, Hellwig E, Auschill TM. The effect of at-home bleaching on the microhardness of six esthetic restorative materials. J Am Dent Assoc 2007;138:978-984.

7. Rotstein I, Dogan H, Avron Y, Shemesh H, Steinberg D. Mercury release from dental amalgam after treatment with 10\% carbamide peroxide in vitro. Oral Surg Oral Med Oral Pathol Oral Radiol Endod 2000;89:216219.

8. Bailey SJ, Swift EJ, Jr. Effects of home bleaching products on composite resins. Quintessence Int 1992;23:489-494.
9. Cooley RL, Burger KM. Effect of carbamide peroxide on composite resins. Quintessence Int 1991;22:817-821.

10. Okte Z, Villalta P, Garcia-Godoy F, Lu H, Powers JM. Surface hardness of resin composites after staining and bleaching. Oper Dent 2006;31:623628.

11. Yu H, Li Q, Lin Y, Buchalla W, Wang Y. Influence of carbamide peroxide on the flexural strength of tooth-colored restorative materials: an in vitro study at different environmental temperatures. Oper Dent 2010;35:300-307.

12. Yu H, Li $\mathrm{Q}$, Hussain $M$, Wang Y. Effects of bleaching gels on the surface microhardness of tooth-colored restorative materials in situ. J Dent 2008;36:261-267.

13. Firoozmand LM, Pagani C. Influence of bleaching treatment on flexural resistance of hybrid materials. Acta Odontol Latinoam 2009;22:75-80.

14. Turker SB, Biskin T. Effect of three bleaching agents on the surface properties of three different esthetic restorative materials. J Prosthet Dent 2003;89:466-473.

15. Garcia-Godoy F, Garcia-Godoy A. Effect of bleaching gels on the surface roughness, hardness, and micromorphology of composites. Gen Dent 2002;50:247-250

16. Monaghan $\mathrm{P}$, Trowbridge $\mathrm{T}$, Lautenschlager E. Composite resin color change after vital tooth bleaching. J Prosthet Dent 1992;67:778-781.

17. Braem $M$, Lambrechts $P$, Vanherle $G$. Clinical relevance of laboratory fatigue studies. J Dent 1994;22:97-102.

18. Ferracane JL, Berge $\mathrm{HX}_{1}$ Condon JR. In vitro aging of dental composites in water--effect of degree of conversion, filler volume, and filler/ matrix coupling. J Biomed Mater Res 1998;42:465-472.

19. Blackham JT, Vandewalle KS, Lien W. Properties of hybrid resin composite systems containing prepolymerized filler particles. Oper Dent 2009;34:697-702.

20. El-Murr J, Ruel D, St-Georges AJ. Effects of external bleaching on restorative materials: a review. J Can Dent Assoc 2011;77:b59.

21. Malkondu O, Yurdaguven H, Say EC, Kazazoglu E, Soyman M. Effect of bleaching on microhardness of esthetic restorative materials. Oper Dent 2011;36:177-186.

22. Yu H, Li O, Cheng $\mathrm{H}$, Wang $\mathrm{Y}$. The effects of temperature and bleaching gels on the properties of tooth-colored restorative materials. J Prosthet Dent 2011;105:100-107.

23. Kwon YH, Shin DH, Yun DI, Heo YJ, Seol HJ, Kim HI. Effect of hydrogen peroxide on microhardness and color change of resin nanocomposites. Am J Dent 2010;23:19-22.

24. Sharafeddin F, Jamalipour G. Effects of 35\% carbamide peroxide gel on surface roughness and hardness of composite resins. J Dent 2010;7:612. 